\title{
A RADIOLOGICAL CHARACTERIZATION OF THE KIWI-I VEHICLE
}

\author{
REMOTE SENSING LABORATORY \\ NELLIS AIR FORCE BASE \\ LAS VEGAS, NEVADA
}

\author{
STEVEN R. RIEDHAUSER \\ BECHTEL NEVADA \\ LAS VEGAS, NEVADA
}

DATE OF WORK: JUNE-NOVEMBER 1998 


\section{Disclaimer}

This report was prepared as an account of work sponsored by an agency of the United States Government. Neither the United States Government nor an agency thereof, nor any of their employees, nor any of their contractors and subcontractors, or their employees, makes a warranty, express or implied, or assumes legal liability or responsibility for the accuracy, completeness, or any third party's use or the results of such use of any disclosed information, apparatus, product, or process or represents that its use would not infringe privately owned rights. Reference herein to any specific commercial product, process, or service by trade name, trademark, manufacturer, or otherwise, does not necessarily constitute or imply an endorsement, recommendation, or favoring by the United States government or an agency thereof or its contractors or subcontractors. The views and opinions of the authors expressed herein do not necessarily state or reflect those of the United States Government or an agency thereof.

Available electronically at http://www.doe.gov/bridge.

Available to the U.S. Department of Energy and their contractors on paper from the -

U.S. Department of Energy

Office of Scientific and Technical Information

P.O. Box 62

Oak Ridge, TN 37831

423.576.8401

Available to the public from the -

U.S. Department of Commerce

National Technical Information Service

5285 Port Royal

Springfield, VA 22161

703.487 .4650 


\title{
A RADIOLOGICAL CHARACTERIZATION OF THE KIWI-I VEHICLE
}

\author{
REMOTE SENSING LABORATORY \\ NELLIS AIR FORCE BASE \\ LAS VEGAS, NEVADA
}

DATE OF WORK: JUNE-NOVEMBER 1998

Steven R. Riedhauser

Project Scientist

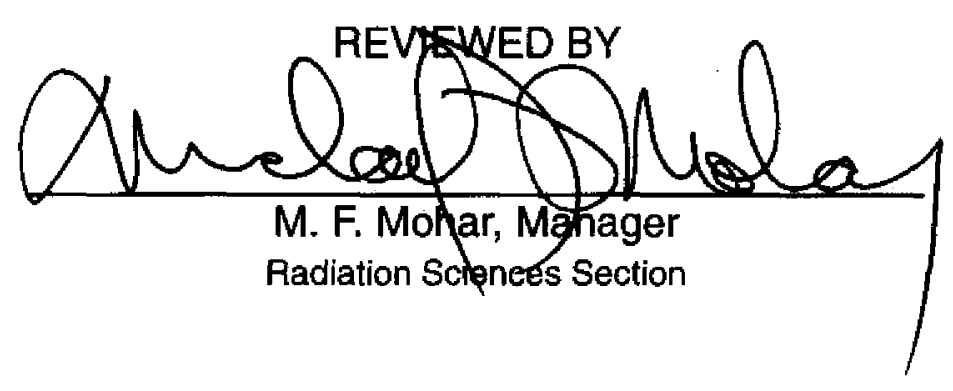

This Document is UNCLASSIFIED

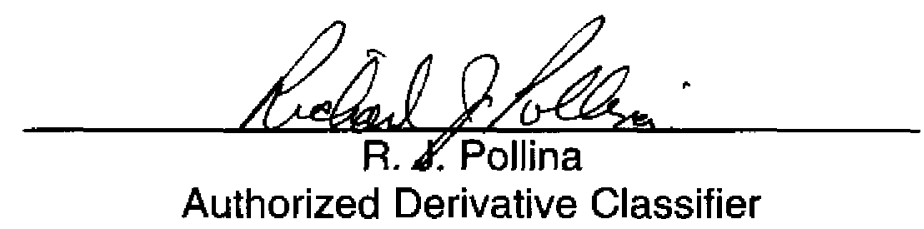

Prepared for the U.S. Department of Energy, Nevada Operations Office Work performed under contract Number DE-AC08-96NV11718 


\section{ABSTRACT}

A review was conducted of the previous Kiwi characterization to understand apparent differences in measured contamination levels observed during recent field work between Kiwi-reported activities and values from another system. The review assessed how the data were processed as well as the assumptions behind the measurement techniques employed. The review included a reassessment of how calculations of conversion factors were performed. The review also checked for errors in the measurements or calculations of the data collected at these sites.

In addition, new characterization measurements were made and new characterization techniques investigated for the Kiwi detector array. These measurements and techniques led to new calculations of conversion factors for the array, which are compared to the previous conversion factors. The new measurements confirmed that the Kiwi detectors are very reproducible in measuring the photopeak count rate from a surface distribution of activity $( \pm 3 \%)$.

Finally, a review was conducted of the various parameters which describe the exponential distribution of activity with depth in the soil. New values have been assigned to the relaxation length and the averaging depth. When combined with the new characterization measurements, they produce a $75 \%$ increase over the previous conversion factor. 


\section{ACRONYMS}

ASL

E-MAD

FIDLER

NIST

REDAR IV

RSL

SGS

TRU
Analytical Services Laboratory

Engine Maintenance Assembly and Disassembly

Field Instrument for the Detection of Low Energy Radiation

National Institute for Standards and Technology

Radiation and Environmental Data Acquisition Recorder, Version IV

Remote Sensing Laboratory

Segmented gate conveyor system

Transuranic 


\section{CONTENTS}

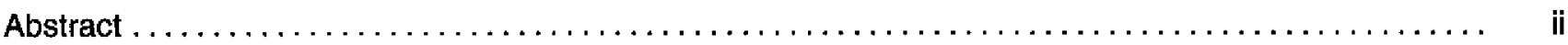

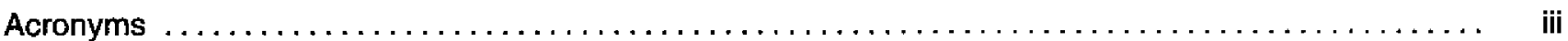

\section{Sections}

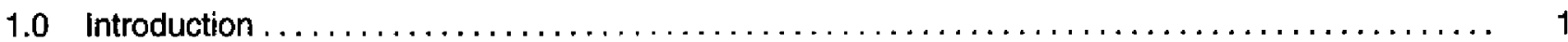

2.0 System Description and Background Information $\ldots \ldots \ldots \ldots \ldots \ldots \ldots \ldots \ldots \ldots \ldots \ldots \ldots \ldots$

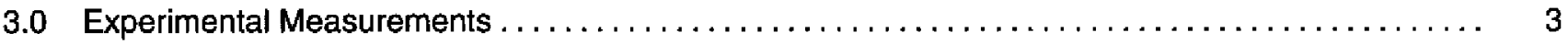

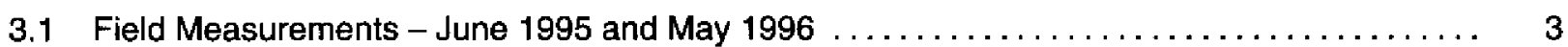

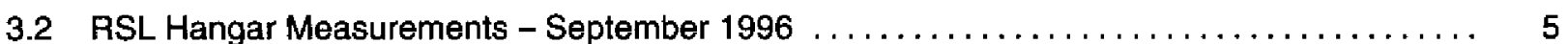

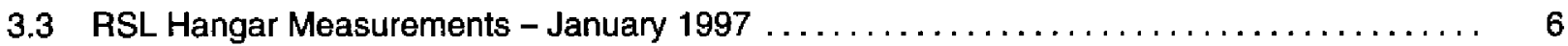

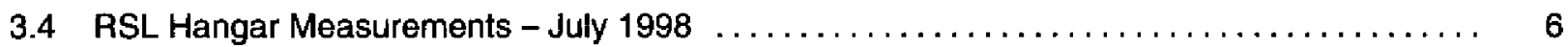

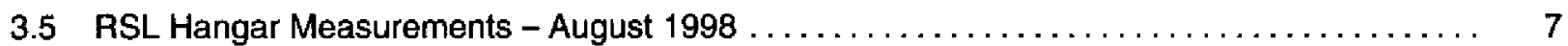

3.6 E-MAD Building Measurements - September $1998 \ldots \ldots \ldots \ldots \ldots \ldots \ldots \ldots \ldots \ldots \ldots$

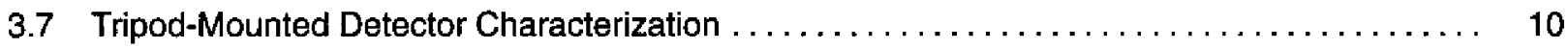

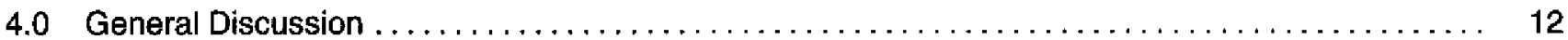

4.1 Effect of Source Distribution on Reported Values $\ldots \ldots \ldots \ldots \ldots \ldots \ldots \ldots \ldots \ldots \ldots \ldots \ldots \ldots \ldots \ldots \ldots \ldots$

4.2 Effect of Averaging Depth on Reported Values $\ldots \ldots \ldots \ldots \ldots \ldots \ldots \ldots \ldots \ldots \ldots \ldots \ldots \ldots \ldots$

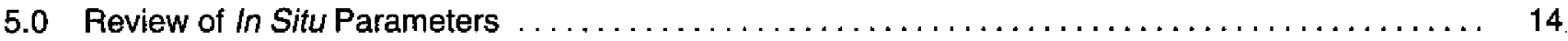

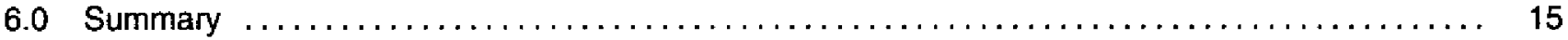

\section{Figures}

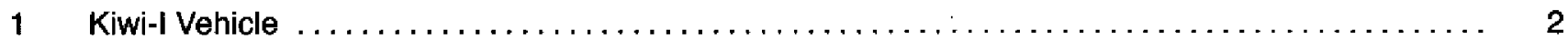

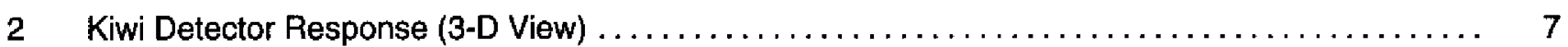

3 Comparison of Measured and Modeled Count Rates $\ldots \ldots \ldots \ldots \ldots \ldots \ldots \ldots \ldots \ldots \ldots \ldots$

4 Count Rates Measured Directly Below the Detector Array $\ldots \ldots \ldots \ldots \ldots \ldots \ldots \ldots \ldots \ldots \ldots \ldots \ldots \ldots$

5 Distributions Producing Equivalent Count Rates $\ldots \ldots \ldots \ldots \ldots \ldots \ldots \ldots \ldots \ldots \ldots \ldots \ldots \ldots$

$6 \quad$ Excavation Depth Dependence on Average Activity $\ldots \ldots \ldots \ldots \ldots \ldots \ldots \ldots \ldots \ldots \ldots \ldots \ldots$

\section{Tables}

3.1 Summary of Three Sets of Simulated Surface-Distributed

${ }^{241}$ Am Measurements.

3.2 Summary of the Various Calculations and Measurements of the Conversion Factors for the Kiwi System

3.3 Summary of the Measurement and Various Model Calculations

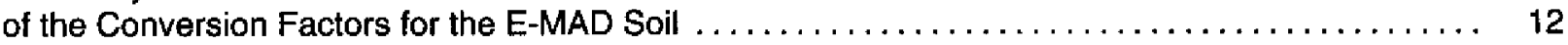

5.1 Summary of Volume Distribution Parameters Used at the Four Sites $\ldots \ldots \ldots \ldots \ldots \ldots \ldots \ldots, 14$

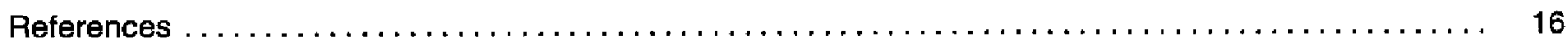




\subsection{INTRODUCTION}

During work at Clean Slate 2 in late May 1998, Thermo NUtech's segmented gate conveyor system (SGS) was being assessed for its suitability for future use at the Clean Slate sites. At that time, a difference was observed between the estimated average plutonium concentration in soil determined by the SGS and that determined in situ by the Remote Sensing Laboratory's (RSL) Kiwi system. While the two systems measure activity in different ways and we have no firm knowledge of the uncertainties in the SGS values, it was felt that a review of the methods and assumptions used by the Kiwi system was necessary. Therefore, RSL initiated a complete analysis of its equipment characterization processes and initiated several new techniques for characterizing the Kiwi.

A review was conducted of all previous work at the Double Tracks and the three Clean Slate sites. This included a review of the measurements made at each site as well as how the data was processed. In particular, the review included a reassessment of how calculations of conversion factors were performed. The review also checked for errors in the measurements or calculations of the data collected at these sites.

\subsection{SYSTEM DESCRIPTION AND BACKGROUND INFORMATION}

The Kiwi-I system* is the result of mounting the detectors and data collecting system from RSL's standard aerial system onto a Chevrolet Suburban vehicle (Figure 1). Six 2- $\times 4-\times 16$-inch sodium iodide (Nal) logs are housed in pods mounted on an angle-iron frame attached in place of the rear bumper. The detectors are approximately $0.7 \mathrm{~m}$ above the ground. In addition, Kiwi has two smaller Nal detectors (a 2- $\times$ 4- $\times$ 4-inch log and a 1-inch-diameter by 1 -inch-long cylinder) for use in very high radiation fields. Signals from all detectors feed into a Radiation and Environmental Data Acquisition Recorder, Version IV (REDAR IV) data-recording system bolted to the floor of the Suburban.

The principal motivation for developing the Kiwi vehicle was to map plutonium contamination (actually, all transuranic isotopes [TRU]) at the Double Tracks site by measuring the $60-\mathrm{keV}$ gamma ray emitted by ${ }^{241} \mathrm{Am}$. To produce a well-defined footprint, a sheet of cadmium shields the Kiwi detector array on the top, rear, and sides, while the end-mounted photomultiplier tubes provide shielding to the front of the detectors. This shielding is more than adequate for attenuating the $60-\mathrm{keV}$ gamma rays of ${ }^{241} \mathrm{Am}$ but does not significantly affect the higher energy radiation from the natural radioisotopes. Cadmium is used instead of lead because, when lead is stimulated by high-energy gamma rays, it emits $X$ rays in the 70-95 keV energy range and these $X$ rays would interfere with the ${ }^{241} \mathrm{Am}$ gamma-ray photopeak. The $X$ rays emitted by cadmium are much lower in energy and do not interfere with the ${ }^{241} \mathrm{Am}$ photopeak.

\footnotetext{
* Kiwi-ll, a newer version of this system constructed in the past year, has capabilities for working in more extensively contaminated areas. The original Kiwi system has now been designated as Kiwi-l; however, throughout this report, the term "Kiwi" will mean Kiwi-l.
} 


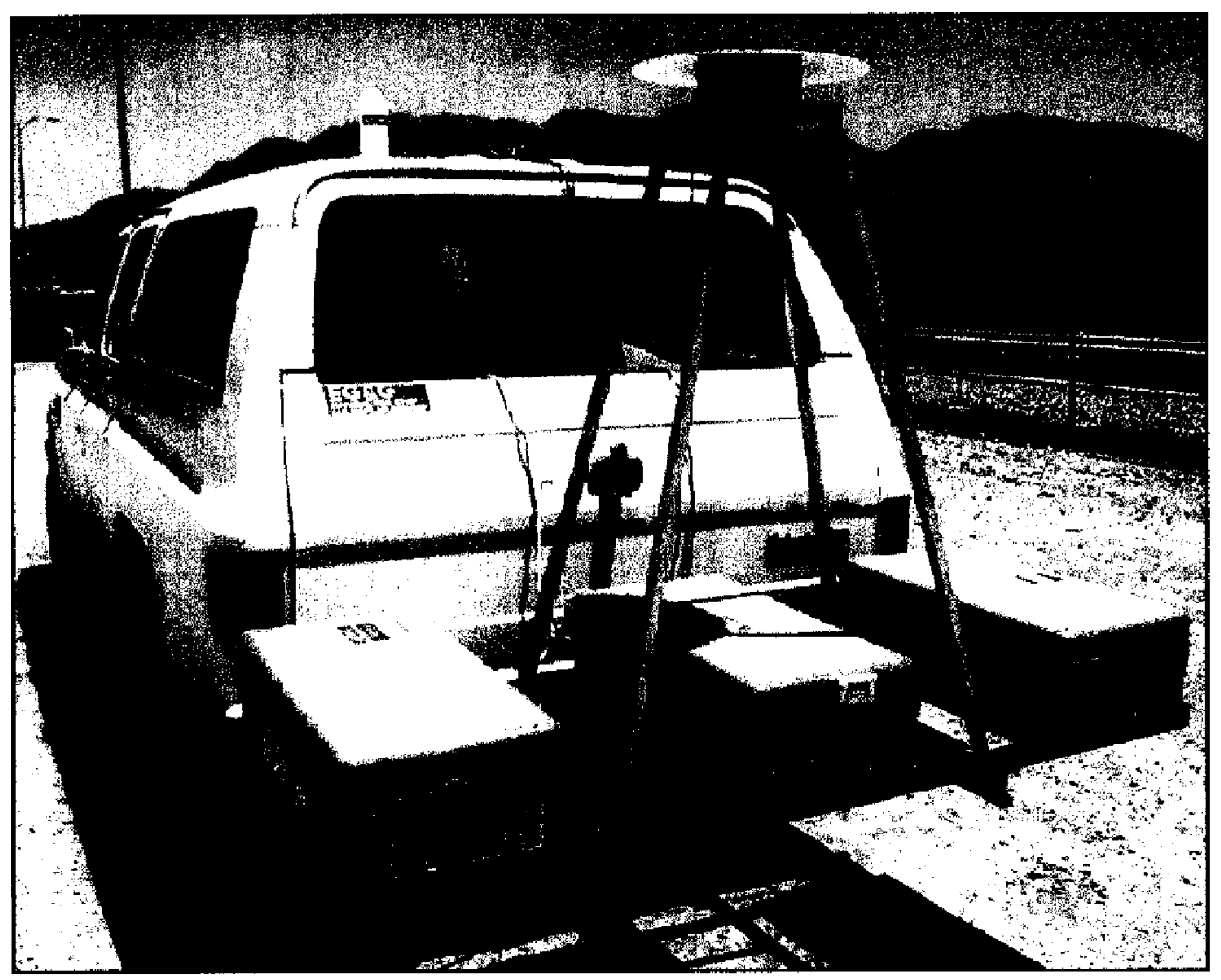

FIGURE 1. KIWI-I VEHICLE. Six Nal logs in the three pods on the rear of the Chevrolet Suburban vehicle detect gamma rays from 241 Am directly beneath and slightly to the side of the pods. Shielding on the sides of the detectors limits the field of view to less than a meter to either side of the pods.

With the specified detector height and the cadmium shielding, the resulting ${ }^{241}$ Am footprint ${ }^{*}$ of the stationary Kiwi system is about $3 \mathrm{~m}$ wide and $1.2 \mathrm{~m}$ long. With the Kiwi travelling at $2.2 \mathrm{~m} / \mathrm{s}(5 \mathrm{mph})$, the footprint for each one-second measurement is about $3 \mathrm{~m}$ wide by $3.4 \mathrm{~m}$ long. This speed is near (or slightly above) the maximum speeds we have been able to drive under off-road conditions. The footprint size for gamma rays emitted by other isotopes will vary with the energy of the gamma ray.

The Kiwi detectors produce voltage pulses which are proportional to the energy of the incident gamma rays. These voltage pulses are processed by the electronics in the REDAR IV system and a complete gamma-ray energy spectrum is recorded during each second of operation. The energy ranges from about $24 \mathrm{keV}$ (at the low-energy cutoff) up to about 4,000 keV (at the high-energy limit of the system). Each one-second spectrum is labelled with position coordinates to locate it within the survey area. Alternatively, if the Kiwi is stationary, then the individual spectra can be summed to produce a single, long-time spectrum taken at a single location. This produces a measurement with better counting statistics.

\footnotetext{
* The area of ground seen by a detector system is called the "footprint." Since gamma rays are exponentially attenuated as they travel through material, the footprintchanges with gamma-ray energy and does nothave asharpedge. The Kiwidetectorarray response for60-keVgamma rays reaches $50 \%$ of its central value about $0.6 \mathrm{~m}$ in front of or behind the array and about $1.5 \mathrm{~m}$ on either side. For the collimated tripod germanium detectors, the footprint was a circle with approximately a 1.2-m diameter.
} 
As gamma rays travel through any material, a certain fraction of them will be scattered and lose some of their energy. The fraction of scattered gamma rays depends on several factors, predominantly the density of the material and the types of atoms in the material. Once a gamma ray is scattered, its energy changes and there is no means to trace it to its parent isotope. Therefore, if the amount of intervening material is known, then the number of unscattered gamma rays can be used to determine the amount of radioisotope present.

The discussion in the preceding paragraph is accurate for the analysis of photopeaks in the spectra collected by Ge detectors. However, when this technique is applied to the analysis of the ${ }^{241}$ Am photopeak count rate using $\mathrm{Nal}$ detectors, some previously unrecognized problems are seen. Since the gamma rays emitted from ${ }^{241} \mathrm{Am}$ have such a low energy compared to the mass of the electron, the gamma rays only lose a small portion of their initial energy when they undergo Compton scattering. The width of the photopeaks in Nal detectors is relatively large; much of the peak is contained in a region which has a width of around $10 \%$ of the peak energy. Thus, most of the $60-\mathrm{keV}$ photopeak is spread over the range from 54 to $66 \mathrm{keV}$. The Compton-scattered gamma rays have energies ranging from $60 \mathrm{keV}$ down to about $48 \mathrm{keV}$. Many of these scattered gamma rays will have enough energy that they will appear to still be part of the unscattered photopeak. These scattered gamma rays will add to the measured count rate, but the photopeak is assumed to be only the result of unscattered gamma rays.

In practice, for each $\mathrm{Nal}$ spectrum, the number of unscattered ${ }^{241} \mathrm{Am}$ gamma rays is calculated from the net counts in the energy range from $50 \mathrm{keV}$ to $70 \mathrm{keV}$. The net counts are the difference between the total counts in this energy range and a scaled sum of the counts in the two background energy ranges from $38-50 \mathrm{keV}$ and $70-82 \mathrm{keV}$. This 3-window analysis process assumes the background in the photopeak window is a linear function of the counts in the two background windows.

On all the transuranic activity plots generated from Kiwi data and published in previous reports, $1,2,3,4,5$ the activity values are derived from an average activity over a $10-\mathrm{m}$ by $10-\mathrm{m}$ area which is $4 \mathrm{~cm}$ deep. The activity values are based on a model which assumes an exponential distribution of the ${ }^{241} \mathrm{Am}$ with depth in the soil, but the activities are converted into an average over the top $4 \mathrm{~cm}$. Depth profile measurements using a germanium detector system at Double Tracks and the three Clean Slate sites indicated that most of the contamination in undisturbed areas was within the top one inch $(2.5 \mathrm{~cm})$. In some locations, a small amount of activity was observed after the top inch was removed, but it was undetectable at two inches $(5 \mathrm{~cm})$. Based on these measurements of the undisturbed areas, $4 \mathrm{~cm}$ was assumed to be the deepest level of activity. The disturbed areas at the sites (near ground zero) had contamination mixed to greater depths, but those areas would be excavated regardless of the amount of activity detected. At each site, only a single model of the radioactive distribution (variation with depth in the soil and the depth over which the activity is averaged) is used. The plots are therefore more-easily understandable since all of the measurements at one site are treated the same. However, the onemodel-per-site may not truly represent the real distribution at every location within the site.

\subsection{EXPERIMENTAL MEASUREMENTS}

\subsection{Field Measurements - June 1995 and May 1996}

The Kiwi was used during the characterization work at the Double Tracks site ${ }^{1,2}$ in June 1995. At that time, a value was needed to relate the observed ${ }^{241} \mathrm{Am}$ photopeak count rate with the ${ }^{241} \mathrm{Am}$ activity 
in the soil. To accomplish this measurement, a Field Instrument for the Detection of Low Energy Radiation (FIDLER) detector was used to find a region at the site with a fairly uniform activity. The Kiwi was parked over this spot where it collected data for slightly more than eight minutes. Following this measurement, a collimated, tripod-mounted germanium detector made five measurements of the activity in the same area using a center measurement and four measurements spaced one meter away in each of the four compass directions. The germanium detector had been previously characterized at the RSL using calibrated sources and well-established procedures.

The contamination was assumed to have an exponential distribution with depth in the soil. The shape of this exponential distribution is described by the relaxation length which was assumed to be $3 \mathrm{~cm}$. The calculated activity in the soil was averaged over the top $4 \mathrm{~cm}$ since the depth profile data taken at Double Tracks and Clean Slate plumes generally did not detect any activity below $2.5 \mathrm{~cm}$. In the few instances when they did see activity $2.5 \mathrm{~cm}$ below the ground surface, there was no activity at the next depth of $5 \mathrm{~cm}$. A value of $1.5 \mathrm{~g} / \mathrm{cm}^{3}$ is often used for the soil density; a value of $0.25 \mathrm{~cm}^{2} / \mathrm{g}$ is used for the attenuation coefficient for soil. These two values were adopted for the Double Tracks and Clean Slate work. Finally, the TRU: ${ }^{241} \mathrm{Am}$ ratio was measured at these sites and a slightly conservative value of 16 was adopted.

One feature of the Double Tracks site is the very narrow contamination plume. This contributed to the problem of finding a location with a relatively constant activity over an area the size of the Kiwi footprint. Even though the activity was not very constant, an average activity value ${ }^{*}$ of $6.02 \mathrm{pCi} / \mathrm{g}$ was assumed to represent the whole region seen by the Kiwi detectors. The germanium detector measured the activity to be $3.32 \mathrm{pCi} / \mathrm{g}$ in the center, with 2.72 and $11.5 \mathrm{pCi} / \mathrm{g}$ along the width of the Kiwi measurement, and 4.43 and $8.14 \mathrm{pCi} / \mathrm{g}$ to the front and back of the Kiwi detectors. Using the TRU: ${ }^{241}$ Am ratio of 16:1, this is a TRU activity of $96.4 \mathrm{pCi} / \mathrm{g}$. The Kiwi recorded 281.6 counts per second (cps) after correcting for the effects of the 3-window extraction, ${ }^{1}$ yielding a conversion factor of 0.34 (TRU pCi $\left./ \mathrm{g}\right) / \mathrm{cps}$. This measurement has an uncertainty resulting from the variation in soil activity measured by the germanium detector of $\pm 30 \%$ and an uncertainty from counting statistics in the Kiwi spectra of $\pm 6 \%$ for an overall uncertainty of $\pm 31 \%$. Therefore, a count rate of $290 \mathrm{cps}$ in the ${ }^{241} \mathrm{Am}$ window would correspond to $100 \mathrm{pCi} / \mathrm{g}$ of TRU material in the top $4 \mathrm{~cm}$ of soil.

The Kiwi was again used during the characterization work at the three Clean Slate sites in April and May 1996. ${ }^{4}$ At this time, another measurement of the conversion factor relating the ${ }^{241}$ Am photopeak count rate with the ${ }^{241} \mathrm{Am}$ activity in the soil was desired to verify the measurement previously made at Double Tracks. To accomplish this measurement, a region at the Clean Slate 3 site was found with an activity which was more uniform than the location at Double Tracks (again, as measured by the count rate of a FIDLER detector). The Kiwi collected data for about eight minutes over this spot. Following this measurement, a collimated, tripod-mounted germanium detector measured the activity in the same area using four measurements around a central measurement.

While the activity was not very constant as measured by the germanium detector $(143 \mathrm{pCi} / \mathrm{g}$ in the center, with 120 and $135 \mathrm{pCi} / \mathrm{g}$ along the width of the Kiwi measurement, and 107 and $259 \mathrm{pCi} / \mathrm{g}$ to

\footnotetext{
- The average activity seen by the detectors can be calculated using several different methods. The method used here treats all five germanium measurements equally to obtain the $6.02 \mathrm{pCl} / g$ value. Alternatively, if the four outer measurements are averaged [ $(2.72+11.5+$ $8.14+4.43) / 4=6.70]$ and that value is then averaged with the central value $[(6.70+3.32) / 2=5.01]$, the result is about $17 \%$ lower than the first method. Another method which has been proposed weighs each germanium-measured activity value by the response of the Kiwidetector at the center of the germanium field-of-view. This method could not even be attempted until the spatial response of the Kiwi was measured in September 1996. It produces an activity value of $3.49 \mathrm{pCi} / \mathrm{g}$ (whlch is highly biased by the central value). The technique chosen was the one which produced the highest average activity and would thus overestimate the activily measured by the Kiwi.
} 
the back and front of the Kiwi detectors), an average activity value of $153 \mathrm{pCi} / \mathrm{g}$ was assumed to represent the whole region seen by the Kiwi detectors. The Kiwi recorded $8481 \mathrm{cps}$ (after correcting for the effects of the 3-window extraction), yielding an ${ }^{241} \mathrm{Am}$ conversion factor of $0.018(\mathrm{pCi} / \mathrm{g}) / \mathrm{cps}$. This measurement has an uncertainty resulting from the variation in soil activity measured by the germanium detector of $\pm 20 \%$ and an uncertainty from counting statistics in the Kiwi spectra of $\pm 2 \%$ for an overall uncertainty of $\pm 20 \%$. This measurement still was considered as somewhat uncertain, so the Clean Slate characterization report ${ }^{4}$ used a conversion factor $20 \%$ higher $\left(0.022[\mathrm{pCi} / \mathrm{g}] / \mathrm{cps}\right.$ for ${ }^{241} \mathrm{Am}$ or $0.35[\mathrm{pCi} / \mathrm{g}] / \mathrm{cps}$ for $\left.{ }^{-T R U}\right)$. The use of the larger conversion factor would overestimate the activity and therefore ensure that any region with an activity just less than the remediation level would be included in the cleanup. In the Clean Slate transuranic activity plots, an ${ }^{241} \mathrm{Am}$ count rate of $280 \mathrm{cps}$ corresponds to $100 \mathrm{pCi} / \mathrm{g}$ of TRU material.

\subsection{RSL Hangar Measurements - September 1996}

In September and early October, a concerted effort was begun to characterize the Kiwi detectors over the entire energy spectrum. Several modifications in positioning and detector capabilities as well as operational techniques had been made over the previous year.

These tests measured the photopeak count rate for individual sources placed at uniform distances along a grid beneath the Kiwi detectors. The initial measurements were conducted along the axes of the grid and extended up to 30 feet to the left, right, front, or back of the center of the detector array. These first measurements indicated two important items for the later measurements. First, they gave a rough indication of the footprint for each energy and the distances when the counting times should be increased to keep the counting statistics reasonable. Second, they highlighted the need for data over the whole grid, since the detector array has no symmetry which can be exploited for modeling off-axis count rates based upon the on-axis measurements.

Five sources were used in the measurements, ${ }^{22} \mathrm{Na},{ }^{60} \mathrm{Co},{ }^{133} \mathrm{Ba},{ }^{137} \mathrm{Cs}$, and ${ }^{241} \mathrm{Am}$. The ${ }^{241} \mathrm{Am}$ source has a National Institute for Standards and Technology (NIST)-traceable activity of $9.24 \mu \mathrm{Ci}$. The other sources had manufacturer-specified activities. In turn, each source was placed at the 1-foot grid intersections on the hangar floor and the REDAR system recorded data for 30 seconds. Then the source was moved to the next grid location. This continued for each grid location out to a distance of 5 feet from the center. For grid rows or columns 6 feet from the center, a 60 -second count time was used. Beyond 6 feet, data were taken on the 8 -foot rows and columns, but only every other intersection (e.g. 8 feet back and $0,2,4,6$, and 8 feet to the right).

Plots of the photopeak count rate versus $(x, y)$-position were constructed for each isotope and a surface conversion factor was calculated from the simulated surface activity density (activity per unit area) and the total count rate. The ${ }^{241} \mathrm{Am}$ photopeak count rate curve falls off even more rapidly with distance than the curves for the other isotopes, which is expected considering that the cadmium shielding on the sides of the detectors is opaque to the low-energy ${ }^{241} \mathrm{Am}$ gamma rays.

The surface conversion factor measured in September 1996 was compared to our previous calculational methods. However, the transformation from a surface conversion factor to a volume conversion factor includes many assumptions which can introduce errors. The calculations used in each method could not be easily isolated from the overall process and compared in a simple manner. An explanation for the apparent discrepancy could not be reached at the time, as funds ran out. 


\subsection{RSL Hangar Measurements - January 1997}

The grid measurements were repeated in January 1997 using a set of four ${ }^{241}$ Am check sources having a total activity of about $37 \mu \mathrm{Ci}$. While only two of the sources used had NIST-traceable activity values, the increase in the total activity over the September 1996 tests (using a $9.2 \mu \mathrm{Ci}{ }^{241} \mathrm{Am}$ source) resulted in lower counting statistics and a smaller overall uncertainty. The higher activity also permitted measurements at distances further from the detector array, but the contribution from these large distances was relatively small. The surface conversion factor was within a few percent of the value determined four months earlier.

\subsection{RSL Hangar Measurements - July 1998}

In July 1998 , the grid measurements were repeated using a single ${ }^{241} \mathrm{Am}$ check source having an activity measured by NIST of about $114 \mu \mathrm{Ci}$. Again, the increase in the total activity over previous tests resulted in lower counting statistics and a smaller overall uncertainty. The uncertainty of the surface conversion factor is dominated by the uncertainty in the source activity. The uncertainty due to the count rate is very small (less than 1\%). Figure 2 shows the response (count rate) of the detector array to the point source as a function of distance from the center of the array.

The results of the September 1996, January 1997, and July 1998 tests are summarized in Table 3.1. As can be seen in the last two rows of the table, the agreement between these three measurements is good. Thus, the Kiwi provides a very precise and reproducible measurement of surface-distributed ${ }^{241} \mathrm{Am}$ activity. The reproducibility of these measurements indicates that the uncertainties associated with the conversion factors are not dependent on the measurement of the gamma rays and the analysis of the gamma ray spectrum. As will be seen later, the uncertainties of the volume-distributed conversion factors arise with the transformation of the surface conversion factor into the volume conversion factor.

The conversion factors for uniform and exponential depth distributions calculated with the July 1998 measurements were converted into volume conversion factors by the following technique. For each grid cell, the surface count rate values were used to simulate the count rates which would be observed from layers of contamination at different depths of burial by scaling the count rates by two numbers. If simulating a uniform distribution, each layer would have the same activity as the surface layer and the first scaling factor would be 1.0. If an exponential distribution is being simulated, then as the depth increases, the activity of that layer decreases by the factor of $\exp \left(-z / z_{0}\right)$ relative to the surface value, where $z$ is the depth of the level and $z_{0}$ is the relaxation length of the depth distribution, or how fast the layers of activity decrease with depth.

The second scaling factor for each layer adjusted the count rate by the attenuation of the gamma rays through the soil. The procedure, called Hangar Surface Extrapolation, assumes the attenuation of the count rate is proportional to the distance through the soil which the gamma rays would travel to reach the center of the detector array. Since the detector array has a finite size of approximately $1.5 \mathrm{~m}$ by $0.5 \mathrm{~m}$ compared to the footprint of about $3 \mathrm{~m}$ by $1.2 \mathrm{~m}$, the distance to the center of the array overestimates the distance which the gamma rays from a typical location must travel. Thus, the calculated attenuation of the gamma rays at the simulated depth will be larger than the true value or, similarly, the calculated count rate will be too low. 


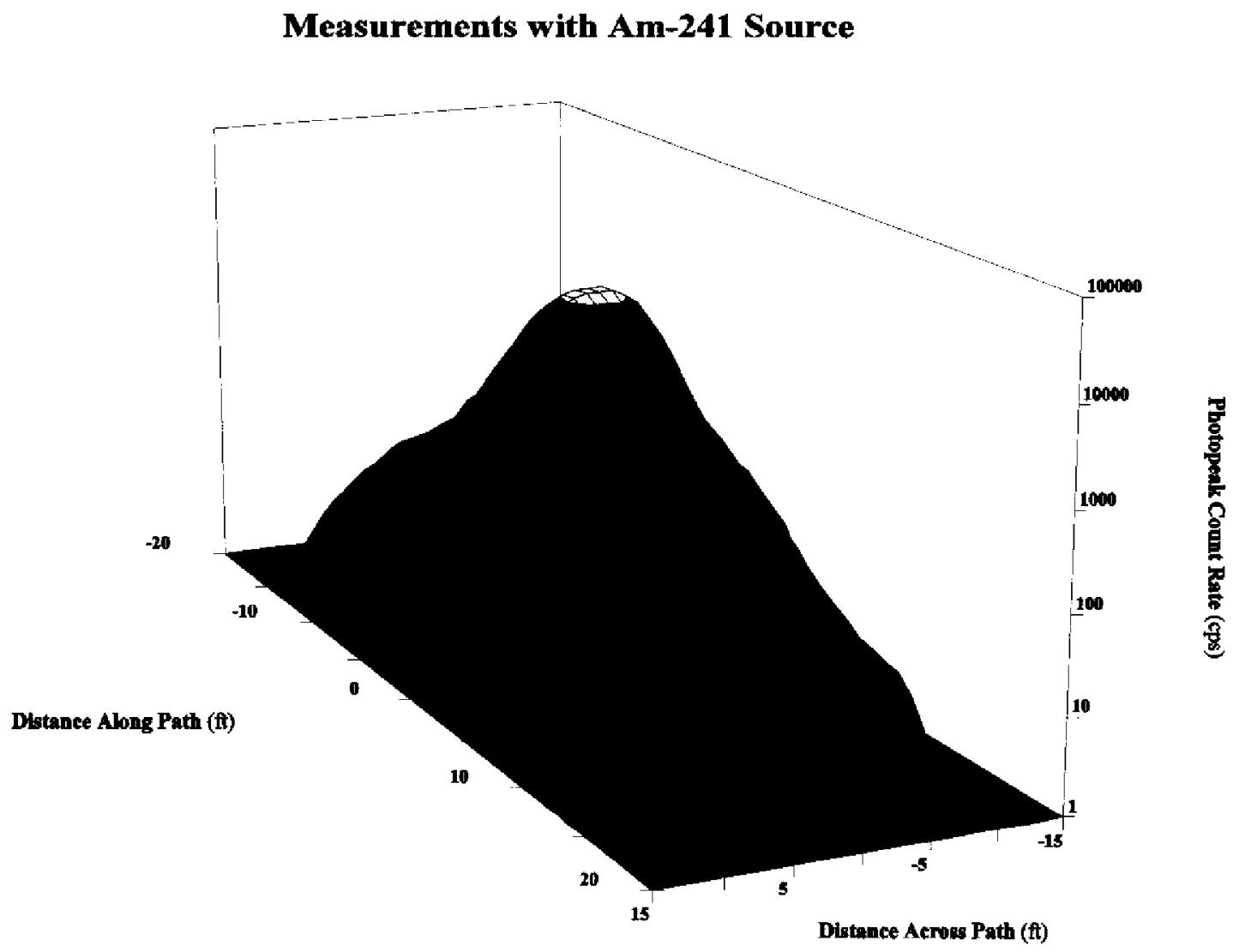

Figure 2. KIWI DETECTOR RESPONSE (3-D VIEW). The data were collected in July 1998 and represent the photopeak count rate for a $114 \mu \mathrm{Ci}{ }^{241} \mathrm{Am}$ source placed at each one-foot grid location. The view is from the "right front bumper" of the vehicle, looking back towards the detector array. The two large valleys to the right of the center are where the vehicle rear tires shield the source from the detectors. The "footprint" discussed in the text is a small, nearly rectangular region outlined by a count rate which is about one-half of the peak value.

\subsection{RSL Hangar Measurements - August 1998}

Following the techniques performed during the hangar measurements in July, three sets of measurements were performed with the same check source under various layers of soil. For each set of measurements, the source was placed at the bottom center of a $60-\mathrm{cm}$ by $60-\mathrm{cm}$ tray, which was then filled with dry soil to the desired thickness. The soil thickness was $1.9 \mathrm{~cm}, 3.8 \mathrm{~cm}$, or $7.6 \mathrm{~cm}$. As the thickness of the soil increased, the Kiwi was elevated on platforms to maintain the same distance between the detectors and the top of the soil which simulated the surface of the ground. In addition to the count rate for each depth, the density of the soil was measured as $1.47 \mathrm{~g} / \mathrm{cm}^{3}$.

A new method to calculate conversion factors, called Parametric Calculation, is based on a parametric fit of the four count rate measurements at $0,1.9,3.8$, and $7.6 \mathrm{~cm}$ depths in the soil. Figure 3 shows the fit of these measured values. Conversion factors for the Kiwi are calculated from these four data points by a linear interpolation between each pair of measurements. The fit to all four measurements is shown strictly for comparison. Since the point-to-point fit matches the four measurements exactly, this parametric fit should more accurately predict the conversion factors. While this technique fits the 
Table 3.1 Summary of Three Sets of Simulated Surface-Distributed ${ }^{241}$ Am Measurements. The uncertainties in the surface conversion factors are dominated by the source uncertainties.

\begin{tabular}{|c|c|c|c|}
\hline Date & September 1996 & January 1997 & July 1998 \\
\hline Activity $(\mu \mathrm{Ci})$ & 9.24 & 37.2 & 113.75 \\
\hline Source Uncertainty & $3.6 \%$ & $-8 \%$ & $1.3 \%$ \\
\hline Source Activity & NIST-traceable & manufacturer-traceable & NIST-measured \\
\hline Measurements made to the front & $\begin{array}{l}5 \text { feet (extrapolated to } \\
7 \text { feet) }\end{array}$ & 10 feet & $\begin{array}{l}6 \text { feet (selected } \\
\text { locations to } 8 \text { feet) }\end{array}$ \\
\hline Measurements made to the back & $\begin{array}{l}5 \text { feet (extrapolated to } \\
7 \text { feet) }\end{array}$ & 10 feet & $\begin{array}{l}6 \text { feet (selected } \\
\text { locations to } 14 \text { feet) }\end{array}$ \\
\hline Measurements made to the left & $\begin{array}{l}\text { assumed symmetric to } \\
\text { right side }\end{array}$ & 10 feet & $\begin{array}{l}6 \text { feet (selected } \\
\text { locations to } 14 \text { feet) }\end{array}$ \\
\hline Measurements made to the right & $\begin{array}{l}6 \text { feet (extrapolated to } \\
8 \text { feet) }\end{array}$ & $\begin{array}{l}\text { assumed symmetric to } \\
\text { left side }\end{array}$ & $\begin{array}{l}6 \text { feet (selected } \\
\text { locations to } 14 \text { feet) }\end{array}$ \\
\hline $\begin{array}{l}\text { Surface Conversion Factor } \\
\text { (nCi/m² per } \mathrm{cps} \text { ) }\end{array}$ & 2.14 & 1.99 & 1.90 \\
\hline Variation from July 1998 & $+12.6 \%$ & $+4.7 \%$ & \\
\hline
\end{tabular}

measured data, its principal disadvantage is that it cannot be extended to other gamma-ray energies and other media without performing the measurements at the various depths of the different media.

Table 3.2 summarizes the results of the various Kiwi calculations for exponentially distributed activities. The calculations based on the extrapolation of the surface activity to various depths (Hangar Surface Extrapolation) fails to model the measurements conducted in August 1998. The hangar measurements recorded significantly more counts at each layer than the Hangar Surface Extrapolation predicts. Thus, it is clear that the Hangar Surface Extrapolation method will calculate conversion factors which are too high.

\subsection{E-MAD Bullding Measurements - September 1998}

To test the ability of our new Parametric Calculation model to predict the activity of contaminated soil, a set of measurements using samples of contaminated soil was made at the Engine Maintenance Assembly and Disassembly Building (E-MAD). The Analytical Services Laboratory (ASL) in Mercury had previously analyzed these 20 samples of Clean Slate 2 soil by gamma spectroscopy. The soil samples were mixed together and spread into a $30-\mathrm{cm}$ by $30-\mathrm{cm}$ pan to a depth of about $10 \mathrm{~cm}$. For $60-\mathrm{keV}$ gamma ray energy, $10 \mathrm{~cm}$ of soil is a good approximation to an infinitely-deep distribution. The small pan of contaminated soil was placed inside the $60-\mathrm{cm}$ by $60-\mathrm{cm}$ pan used for the RSL hangar measurements. This outer pan was filled to the same depth with the soil used in the RSL hangar measurements, so that any gamma rays leaving the contaminated soil through the sides of the inner pan would travel through the appropriate depth of soil and thus be attenuated before reaching the Kiwi detectors. The pan of contaminated soil was measured on a grid system with the Kiwi detectors in the same setup 


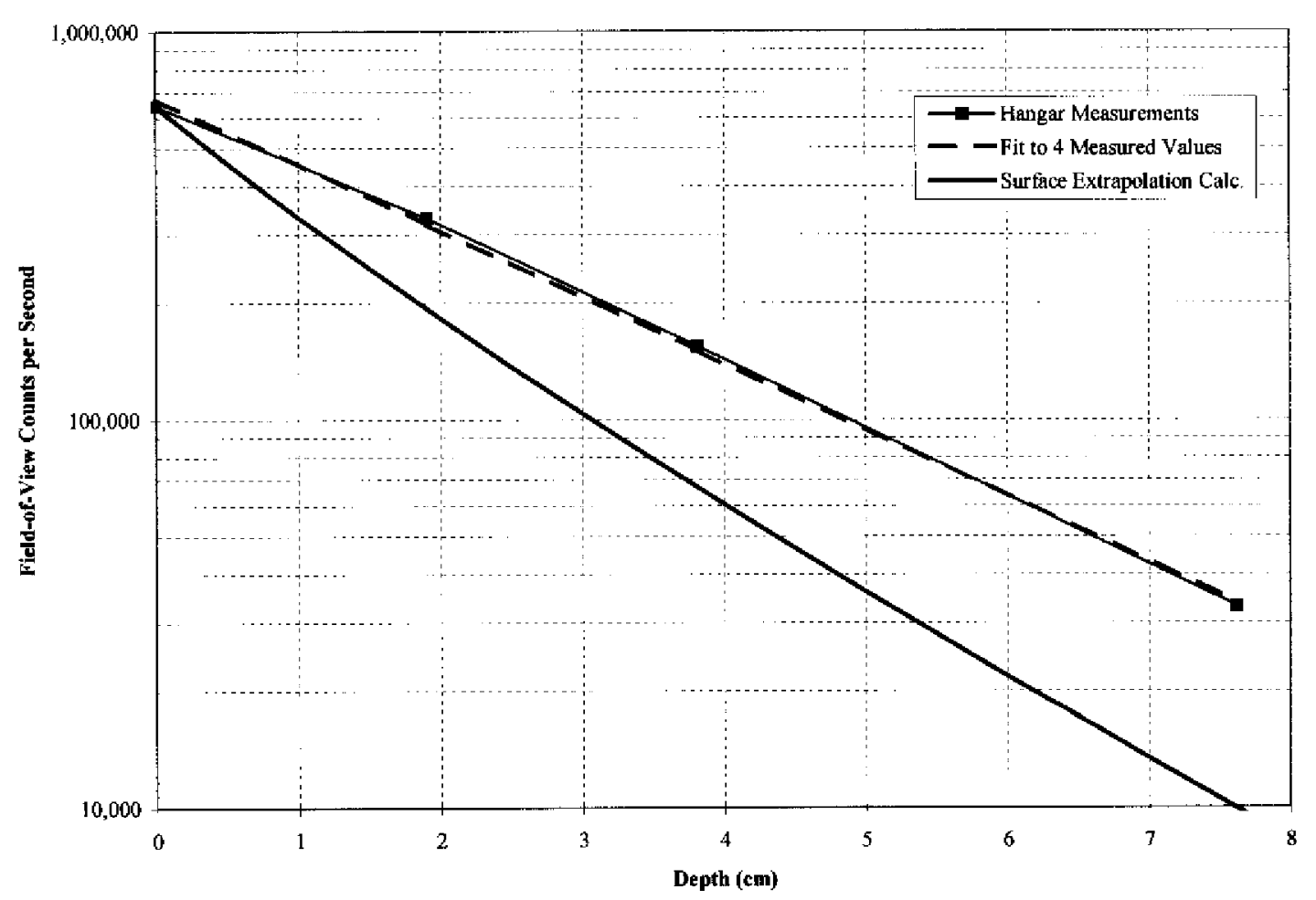

FIGURE 3. COMPARISON OF MEASURED AND MODELED COUNT RATES. The count rates from the ${ }^{241} \mathrm{Am}$ source with $0,1.9,3.8$, and $7.6 \mathrm{~cm}$ of clean soil overburden are shown by the squares. The detector-to-soil surface distance was constant for these measurements; the sour-to-detectordistance increases slightly as the source is placed under thicker layers of soil. Two independent fits to these four data points were investigated; the dashed curve is an exponential fit to the cunt rate at all four depths, while the thin solid line is a fit to each pair of measurements. The thick, solid curve is predicted count rate based on only the surface measurement in which the count rate in each grid cell is attenuated by the amount of soil between the cell center and the center of the detectorarray, the Hangar Surface Extrapolation process.

as was performed with the ${ }^{241} \mathrm{Am}$ check sources discussed in Sections 3.2 through 3.5. The measurements were conducted on the E-MAD building floor since that was a large area equipped to handle packaged contaminated soil.

The principal drawback with these measurements was the low activity of the contaminated soil. The ASL-reported activities of the 20 samples averaged a value of $183 \mathrm{pCi} / \mathrm{g}( \pm 8 \%)$ for the pan of $12.5 \mathrm{~kg}$ of soil. Actually, only two of the samples had any significant activity, but it was deemed better to collect the data using lower activity soil in the desired configuration than to use only the high activity soil in a configuration which would not be as useful. The total ${ }^{241} \mathrm{Am}$ activity in the soil was $2.3 \mu \mathrm{Ci}$, which is much lower than any of the sources used in the hangar measurements. The low activity forced the measurement time at each grid location to be much larger than the time needed for the hangar measurements. Instead of the 0.5-, 1-, or 2-minute measurements in the hangar, the measurements at the E-MAD facility were 10 minutes in length. To compensate for the increased times, measurements were collected at $60-\mathrm{cm}(2-f \circ o t)$ intervals on the grid instead of $30-\mathrm{cm}(1-$ foot $)$ intervals. 
Table 3.2 Summary of the Various Calculations and Measurements of the Conversion Factors for the Kiwi System. The same model parameters are used as were originally assumed for the Double Tracks and Clean Slate 3 field estimates. The "Error" listed in the table is a combination of the uncertainty of any measurements and an error associated with the model accepted for the soil distribution. The model errors are based on varying the exponential distribution model parameters through the range of values which the parameters might expect to have. The measurement uncertainties and the model errors add "in quadrature" to produce the error listed in the table.

\begin{tabular}{lccc}
\hline \multicolumn{1}{c}{ Method } & \multicolumn{2}{c}{$\begin{array}{c}\text { Conversion Factor for } \\
\text { Exponential Depth Distribution }\end{array}$} & \\
\cline { 2 - 3 } & (TRU pCi/g)/cps & $\begin{array}{c}\text { Error } \\
(+/-)\end{array}$ & $\begin{array}{c}\text { Ratlo to New } \\
\text { Value }\end{array}$ \\
\hline Field Measurements & $0.34^{*}$ & $60 \%$ & 0.41 \\
Double Tracks Field Estimate & $0.29^{*}$ & $60 \%$ & 0.35 \\
Clean Slate 3 Field Estimate & & & \\
Calculational Methods & 1.00 & $50 \%$ & 1.22 \\
Hangar Surface Extrapolation & 0.82 & $40 \%$ & 1.00 \\
\hline Parametric Calculation (3-window) & & & \\
\hline
\end{tabular}

*A value of 0.35 was used to conservatively plot the Double Tracks and Clean Slate dala.

In addition to using a wider-spaced grid for the measurements, the planned second and third sets of measurements were limited to the twelve grid locations nearest the detector array. Six more measurements were made directly beneath the detector array. These additional sets of data were intended to track any changes in the count rate as the soil was remixed, and thus judge the uniformity of the soil contamination. Figure 4 shows the count rate for the nine measurements made directly beneath the detector array. There are definite indications that a uniform mixture was not obtained until the third mixing of the soil (before the third set of measurements). The last entry in the graph is the average of the previous nine measurements; the error bars of this last entry reflect the smaller uncertainty resulting from the nine almost-identical measurements.

As discussed above, the second and third sets of measurements were confined to locations near the center of the grid. The count rates for the outlying grid locations were extrapolated from the inner locations by reconstructing the shape of the response curve from the first set. This extrapolation would guarantee that the shape of the response function was the same for all three sets of measurements, while the total number of counts varied according to the measurements actually taken.

The results of the measurements of the uniformly contaminated soil at E-MAD are presented in Table 3.3. As shown in section 3.5, the Hangar Surface Extrapolation calculation produces less satisfactory agreement than the parametrization calculation.

\subsection{Tripod-Mounted Detector Characterization}

In addition to the grid measurements with the Kiwi, a set of simulated surface-distribution measurements was taken in July 1998 with a collimated, tripod-mounted germanium detector. The collimator completely covered the sides and extended about $3.8 \mathrm{~cm}$ below the bottom of the detector. These 


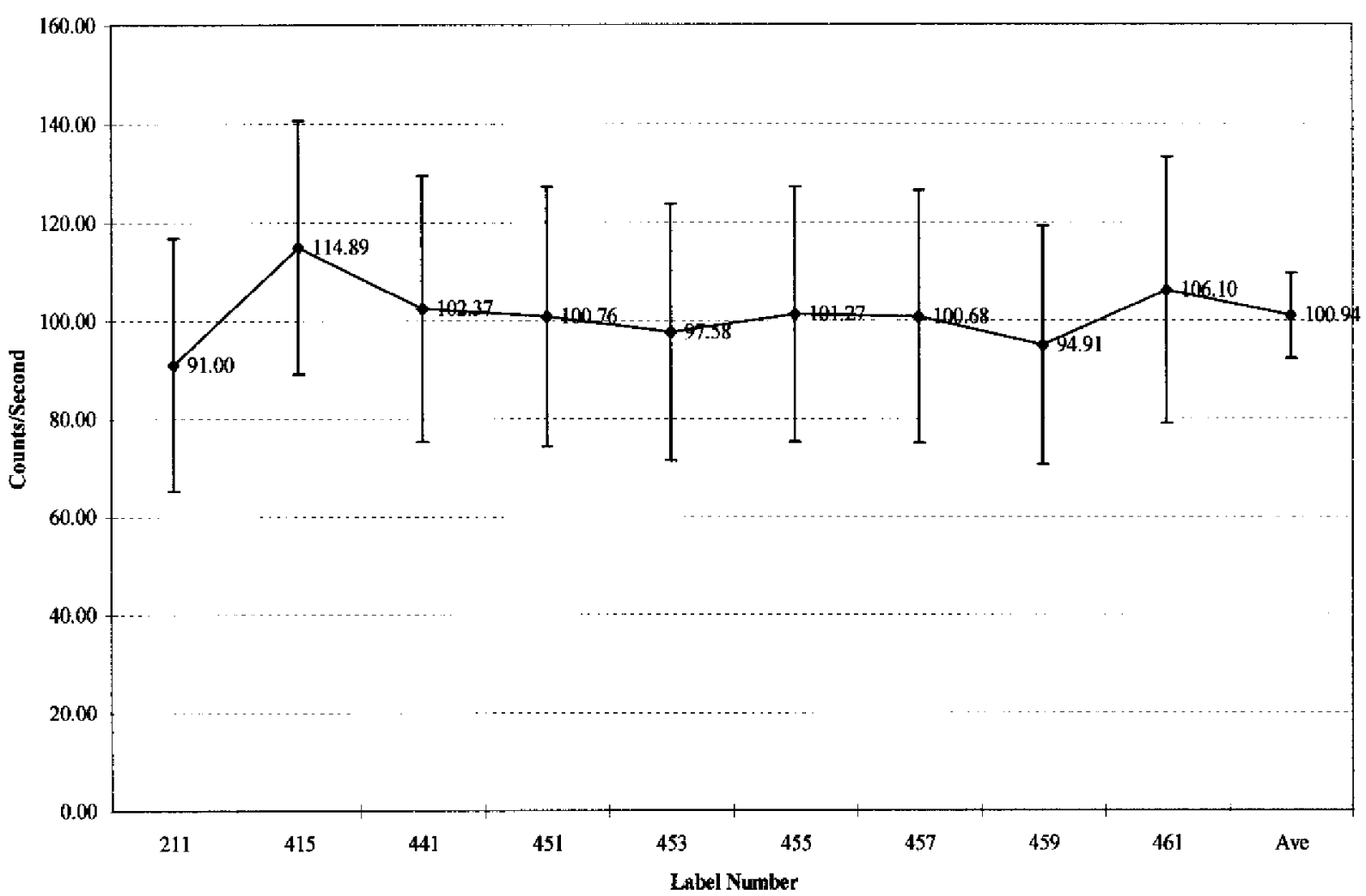

FIGURE 4. COUNT AATES MEASURED DIRECTLY BELOW THE DETECTOR ARRAY. A total of nine measurements were taken directly beneath the Kiwi-l detectorarray. Between each of these measurements, the box of contaminated soil was shaken and tumbled to mix its contents. If there were any large hot particles in the soil, the mixing should place these particles near the top of the soil on some measurements and near the bottom on others. It appears that after the first two measurements the soil was quite uniform.

measurements were conducted in the same manner as the Kiwi measurements. The ${ }^{241} \mathrm{Am}$ source was placed on the grid locations and the count rates from all locations were summed and then divided by the total source activity. The surface conversion factor for the tripod system is $212 \mathrm{nCi} / \mathrm{m}^{2} \mathrm{per} \mathrm{cps}$. Based on our previous method of characterizing the germanium detectors, this same detector (with collimator attached to the tripod and suspended from a hoist) had a surface conversion factor of $176 \mathrm{nCi} / \mathrm{m}^{2}$ per cps. For comparison purposes, with the collimator covering only the sides of the detector and flush with the bottom of the detector, the conversion factor is $71 \mathrm{nCi} / \mathrm{m}^{2}$ per $\mathrm{cps}$, while without any collimator, the bare detector conversion factor is $12 \mathrm{nCi} / \mathrm{m}^{2}$ per cps.

Thus, the surface conversion factor for the tripod-mounted germanium detector, calculated in two different ways, produces approximately the same result. This indicates that if there is a problem with the other conversion factors calculated for this detector, the problem must arise from the modeling of the activity with depth in the soil. 
Table 3.3 Summary of the Measurement and Various Model Calculations of the Conversion Factors for the E-MAD Soll. The Hangar Surface Extrapolation calculation underestimates the count rate from sources under the soil surface; therefore, the conversion factors are incorrect. The calculation predictions are presented here for comparison purposes.

\begin{tabular}{|c|c|c|c|}
\hline \multirow[b]{2}{*}{ Method } & \multicolumn{2}{|c|}{$\begin{array}{c}\text { Conversion Factor for } \\
\text { Uniform Depth Distribution }\end{array}$} & \multirow[b]{2}{*}{$\begin{array}{c}\text { Ratio to E-MAD } \\
\text { Value }\end{array}$} \\
\hline & $\begin{array}{l}\text { (TRU pCi/g) } \\
\text { /cps }\end{array}$ & $\begin{array}{l}\text { Error } \\
(+/-)\end{array}$ & \\
\hline \multicolumn{4}{|l|}{ 3-Window Algorithm } \\
\hline $\begin{array}{l}\text { E-MAD Measurement } \\
\text { Parametric Calculation }\end{array}$ & $\begin{array}{l}0.74 \\
0.77\end{array}$ & $\begin{array}{l}15 \% \\
20 \%\end{array}$ & $\begin{array}{c}1.0 \\
1.04\end{array}$ \\
\hline Hangar Surface Extrapolation & 1.03 & $40 \%$ & 1.39 \\
\hline
\end{tabular}

\subsection{GENERAL DISCUSSION}

\subsection{Effect of Source Distribution on Reported Values}

The Kiwi system records the number of gamma rays incident on the detectors. The photopeak count rate in the detector array depends on the type and amount of material between the radioisotope and the detectors. Since the detectors are approximately the same distance above the ground at all times, the only intervening material to consider is the soil. First, consider a thin layer of ${ }^{241} \mathrm{Am}$ at different depths in the soil. Figure 5(a) indicates the relative amounts of activity 1) on the surface, 2) $2.5 \mathrm{~cm}$ below the surface, and 3) $5 \mathrm{~cm}$ below the surface, all of which produce the same count rate in the detectors. For each $2.5 \mathrm{~cm}$ of depth, approximately twice as much americium is needed to produce the same count rate.

Figure 5(b) shows the same analysis for americium uniformly and exponentially distributed with depth. Note that a true exponential never reaches a value of zero. Also, as the radioisotope extends further into the soil, the amount of activity at the surface decreases, but the total amount of activity (the integral under the curve) increases. This is simply a consequence of what was seen in Figure 5(a) with the thin layers of radioisotopes. As the relaxation length of the distribution continues to increase, the exponential distribution becomes the uniform distribution.

\subsection{Effect of Averaging Depth on Reported Values}

If most of the radioisotope is contained near the surface of the soil, the depth of soil over which the radioactivity is averaged has a strong influence on the average activity. For instance, consider a surface contamination in which the top layer of soil is excavated and analyzed. The average activity for different excavated soil depths is shown in Figure 6. If a surface deposition of americium is excavated with $1 \mathrm{~cm}$ of soil, the average activity will be twice as much compared to excavating $2 \mathrm{~cm}$ of soil or four times the average activity of a $4 \mathrm{~cm}$ excavation (Figure 6[a]).

If an exponential distribution with a relaxation length of $0.5 \mathrm{~cm}$ is considered, the curves in Figure $6(\mathrm{~b})$ arise. Note that the activity for the $1-\mathrm{cm}$ excavation is not quite twice the activity for the 2 -cm excavation 

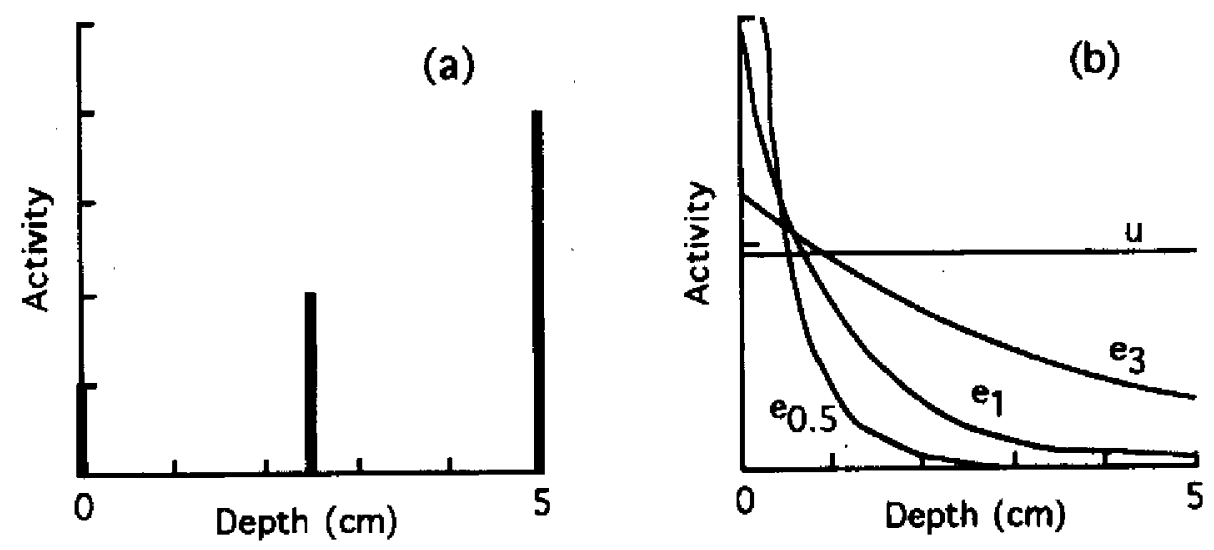

FIGURE 5. DISTRIBUTIONS PRODUCING EQUIVALENT COUNT RATES. (a) If a certain photopeak count rate is produced by an amount of ${ }^{241} \mathrm{Am}$ on the surface of the soll, twice as much ${ }^{241} \mathrm{Am}$ buried beneath $2.5 \mathrm{~cm}$ of soil or four times as much buried beneath $5 \mathrm{~cm}$ of soil will also produce the same detector count rate. (b) The uniform distribution and the three exponential distributions (with relaxation lengths of $0.5,1$, and $3 \mathrm{~cm}$ ) shown will produce equivalent count rates in a detector.

since the 2-cm excavation picked up more radioactive material than the $1-\mathrm{cm}$ excavation. However, the 2-cm average is nearly twice the 4-cm average since almost all of the activity from this distribution is contained in the top $2 \mathrm{~cm}$ of soil (cross-reference Figure $5[\mathrm{~b}]$ ).

If we consider an exponential distribution with a relaxation length of $3 \mathrm{~cm}$, the results are shown in Figure 6(c). Referring to Figure 5(b), note that a significant amount of activity is present below each of the excavation limits. Thus the average activity decreases with deeper excavations but does not follow a simple quantifiable relation with depth, such as $4: 2: 1$.
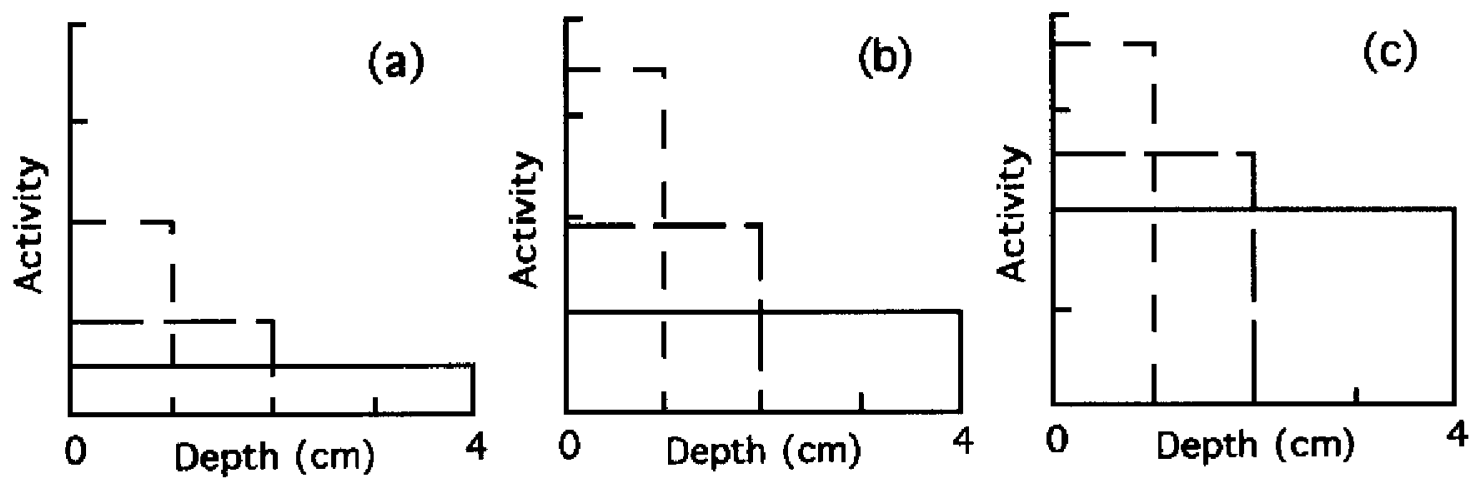

FIGURE 6. EXCAVATION DEPTH DEPENDENCE ON AVERAGE ACTIVITY. The average activity in soil excavated to depths of 1,2 , and $4 \mathrm{~cm}$ for (a) a surface distribution, (b) an exponential distribution with a relaxation length of $0.5 \mathrm{~cm}$, and (c) an exponential distribution with a relaxation length of $3 \mathrm{~cm}$. 


\subsection{REVIEW OF IN SITU PARAMETERS}

In parallel with the recharacterization effort, the parameters used to model the radioactivity in the soil at the Double Tracks and the three Clean Slate sites were reinvestigated. The measured transuranicto-americium ratio (TRU:241 Am) of $16: 1$ was found to be sufficiently accurate. An extensive review of the literature, focusing on the Nevada Applied Ecology Group data from the 1970s and the Radionuclide Inventory and Distribution Program data from the 1980 s indicated that the exponential relaxation length previously chosen for these four sites was too large. The use of a relaxation length of $1.7 \mathrm{~cm}$ instead of the previous $3.0 \mathrm{~cm}$ will reduce the conversion factor by about $14 \%$.

The soil density and mass attenuation coefficient values used previously match some of the values measured in Summer 1998 and, even if these values changed, they would not contribute significantly to any change in the conversion factor. The averaging depth was chosen as $4 \mathrm{~cm}$ in the previous work. A new value of $5 \mathrm{~cm}$ is now chosen. The variation of the parameters and their resulting uncertainties are listed in Table 5.1. The question of whether there was any clean overburden at the sites was not addressed in the past, but if it can be shown that there is some overburden, that could lead to an additional conversion factor change. An overburden layer of $4 \mathrm{~mm}$ would produce an increase in the conversion factor of $13 \%$. Currently we assume no overburden.

The newly recommended values produce a conversion factor of $0.61 \mathrm{pCi} / \mathrm{g}$ per $\mathrm{cps}$ which is a change to the previous conversion factor $(0.35 \mathrm{pCi} / \mathrm{g}$ per $\mathrm{cps})$ of $+75 \%$.

Table 5.1 Summary of Volume Distribution Parameters Used at the Four Sites. The Probable Range is the range of values which this parameter might be expected to have based both on the uncertainty in its measurement and the range of values published in the literature.

\begin{tabular}{|c|c|c|c|c|}
\hline \multirow[b]{2}{*}{ Parameter } & \multirow{2}{*}{$\begin{array}{l}\text { Previous } \\
\text { Value }\end{array}$} & \multirow{2}{*}{$\begin{array}{l}\text { Probable } \\
\text { Range }\end{array}$} & \multicolumn{2}{|c|}{ Conversion Factor Variation (\%) } \\
\hline & & & Most Negative & Most Positive \\
\hline TRU:241Am Ratio & 16 & $14-17$ & -12.50 & +6.30 \\
\hline Relaxation Length (cm) & 3 & $1.4-2.0$ & -18.00 & -8.00 \\
\hline Averaging Depth (cm) & 4 & $5.0-2.5$ & -17.00 & +43.00 \\
\hline \multicolumn{5}{|c|}{$\begin{array}{l}\text { The following variations are based on the newly recommended relaxation length of } 1.7 \mathrm{~cm} \text { and } \\
\text { averaging depth of } 5 \mathrm{~cm}\end{array}$} \\
\hline $\begin{array}{l}\text { Attenuation Coeff. } \\
\left(\mathrm{cm}^{2} / \mathrm{g}\right)\end{array}$ & 0.25 & $0.24-0.28$ & -1.80 & +5.50 \\
\hline Soil Density $\left(\mathrm{g} / \mathrm{cm}^{3}\right)$ & 1.5 & $1.6-1.3$ & -3.50 & +8.70 \\
\hline Total Uncertainty & & & -28.00 & +36.00 \\
\hline
\end{tabular}




\subsection{SUMMARY}

A recharacterization of the Kiwi system has been completed. A detailed review of the previous characterization found no obvious errors in the techniques or procedures. One conclusion from the review is that the geometry of the detectors, relative to the source, is sufficiently different from past detector systems that new calculational tools for the Kiwi were developed. The recharacterization demonstrated that the measurement of surface activity by the Kiwi is reproducible.

The review of the model parameters describing the distribution of the contamination in the soil demonstrated a need for some changes. Conversion factors based on the new site parameters indicate that the original conversion factors were low (underestimated the activity present for a specific count rate) by about $75 \%$. 


\section{REFERENCES}

1. Riedhauser, S.R. and W.J. Tipton. In Situ Radiological Surveying at the Double Tracks Site. Report No. DOE/NV/11718-013; Bechtel Nevada, Las Vegas, NV, 1996.

2. Double Tracks Test Site Characterization Report. Report No. DOE/NV-445; U.S. Department of Energy, Las-Vegas, NV, 1996. (Reference 1 is included as Appendix D of reference 2.)

3. Double Tracks Closure Report. Report No. DOE/NV/11718-113; Bechtel Nevada, Las Vegas, NV, 1997.

4. Clean Slate 1 Corrective Action Decision Document Corrective Action Unit No. 412. Report No. DOE/NV-472, revision 1; U.S. Department of Energy, Las Vegas, NV, 1997.

5. Riedhauser, S.R. An In Situ Radiological Survey Conducted During Remediation Activities at the Clean Slate 1 Site. Report No. DOE/NV/11718-218; Bechtel Nevada, Las Vegas, NV, 1998. 


\section{DOE/DP}

J. A. Weidner, CDR USN

(1)

K. D. Lachman

M. L. Sanchez

IT

L. Wille

BN

P.P. Guss

R. K. Kulm
(1)

WAMO

RSL

(1)

(1)

\section{BN (continued)}

K. R. Lamison, Jr. RSL

M. F. Mohar RSL

J. T. Mitchell LVAO

S. R. Riedhauser RSL

M. D. Shotton RSL

A. J. Will

RSL

(1)

(1)
RESOURCE CENTERS

Public Reading Facility

RSL

TIRC

WAMO

(30)

(1)

(1)

OSTI

(2)

\author{
A RADIOLOGICAL CHARACTERIZATION OF \\ THE KIWI-I VEHICLE \\ REMOTE SENSING LABORATORY \\ NELLIS AIR FORCE BASE \\ LAS VEGAS, NEVADA \\ DOE/NV/11718--298 \\ DATE OF WORK: JUNE-NOVEMBER 1998 \\ DATE OF REPORT: MARCH 1999
}

